\title{
CORRESPONDENCE
}

The Editor,

\section{Journal of Glaciology}

SIR,

\author{
One peculiar ice-melt pattern explained, \\ another peculiar pattern observed
}

The nearly hexagonal melt patten observed by Timco and Coveney (1980) results from organized convective cells in the overlying melt water. Timco and Coveney found this hexagonal pattern when a horizontal sheet of laboratory-grown fresh-water ice melted in a warm room to yield water up to $25 \mathrm{~mm}$ thick on top of the ice. They also observed worm-like channels (c. $2 \mathrm{~mm}$ diameter) in the ice. I have found similar channels under similar conditions and I speculate that these channels result from a process called brine drainage. I have also observed a melt pattern (Figs 1 and 2) with a striking resemblance to that observed by Timco and Coveney under vastly different physical circumstances: a vertical ice sheet melting in salt water through the action of surface waves. I can offer no explanation for the pattern.

First, the melt pattern observed by Timco and Coveney results from convection in the overlying water which is characterized by the Rayleigh number. The Rayleigh number is defined as

$$
(R a)=\frac{g \Delta \rho d^{3}}{\rho \kappa \nu}
$$

where $g$ is the acceleration of gravity $\left(9.8 \times 10^{3} \mathrm{~mm} \mathrm{~s}^{-2}\right), \rho$ the fluid density, $\Delta \rho$ is the density difference between the upper and lower surfaces, $d$ is the thickness of the fluid, $\kappa$ is the thermal diffusivity $\left(0.14 \mathrm{~mm}^{2} \mathrm{~s}^{-1}\right)$, and $\nu$ is the kinematic viscosity $\left(1.8 \mathrm{~mm}^{2} \mathrm{~s}^{-1}\right.$ at $\left.0^{\circ} \mathrm{C}\right)$. Convection occurs because the anomalous dependence of density on temperature yields less dense cold water beneath more dense warm water. The maximum density difference that can be used to characterize the convection is given by

$$
\begin{gathered}
\Delta \rho=\rho\left(4^{\circ} \mathrm{C}\right)-\rho\left(0^{\circ} \mathrm{C}\right), \\
\Delta \rho / \rho \approx 1.3 \times 10^{-4} .
\end{gathered}
$$

Turner (1973) gives the critical Rayleigh number, $(R a)_{\mathrm{c}}$, as about 1000 which occurs in this case for $\mathrm{d} \approx 7 \mathrm{~mm}$.

The convection occurs in a hexagonal pattern for two reasons. First, because the room temperature was $+15^{\circ} \mathrm{C}$, the mean water temperature was probably increasing, and Krishnamurti (1968) shows that convection near $(R a)_{\mathrm{c}}$ occurs in a hexagonal pattern when the mean fluid temperature is changing. Second, when the fluid properties are functions of temperature, Turner (1973) states that a stable hexagonal pattern can exist for $(R a)$ just above $(R a)_{c}$.

The hexagonal pattern in the ice results from the hexagonal convection cells impressing themselves on the ice surface. The ice melts slower below the narrow plumes of ascending water while the ice melts faster in the middle of the hexagons where the warm water is descending. Once the melt pattern begins to form, the deformation of the ice surface locks the convective pattern in place to further accentuate the melt pattern. At the final depth of $25 \mathrm{~mm}, R a \approx 10^{5}$, the convection is still not turbulent (Turner, 1973), hence the melt pattern still persists. Next I have also observed an unusual melt pattern similar to the one observed by Timco and Coveney in an experiment to determine the heat transfer by surface waves in salt water to a vertical ice wall. I placed a fresh-water ice block that measured $0.4 \mathrm{~m} \times 0.6 \mathrm{~m} \times 0.2 \mathrm{~m}$ in a wave tank with the large ice face parallel to the crest of deep water waves generated at the far end of the tank $2 \mathrm{~m}$ away. The waves had an amplitude of $25 \mathrm{~mm}$ and a period of $0.4 \mathrm{~s}$; the water had a salinity of $34 \%$ o and a temperature of $4{ }^{\circ} \mathrm{C}$. Additional details of the experiment are given in Martin, Josberger, and Kauffman in the appendix to Josberger [ [ 1978 ]. Figure 1 is a side view of the ice after melting for $40 \mathrm{~min}$ and Figure 2 is a close up of the cusps in Figure 1. The cusps only appear in the ice from a depth equal to the inverse of the wave number up to the lowest excursion of the water surface. The similarity to Figure 1 of Timco and Coveney is remarkable, although in my case the degree of hexagonality is less. In the wavegenerated case an explanation based on Rayleigh convection does not seem applicable and I can offer no satisfactory explanation. 


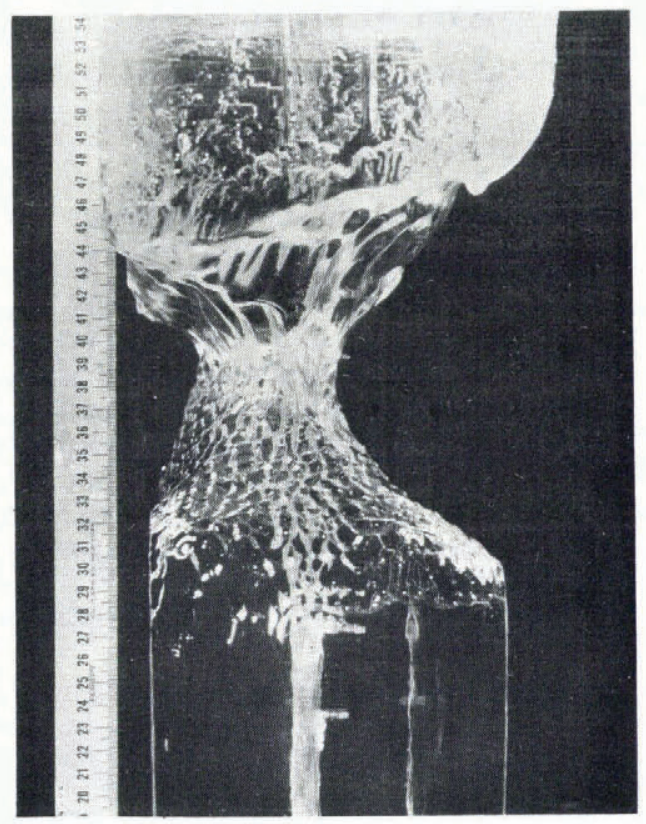

Fig. 1 .

Finally, I too have observed worm-like channels in fresh-water laboratory-grown ice when I let the ice warm from approximately $-10^{\circ} \mathrm{C}$ to near zero overnight. I can only speculate that the holes occur when, upon warming, the ice surrounding brine pockets reaches the melting point, which is slightly below $0{ }^{\circ} \mathrm{C}$ due to the saline freezing-point depression and melting begins. Gravity then keeps the more dense brine at the bottom of the hole where it continues to melt through the ice to form the observed channels. The initial brine pockets form during the freezing process as small amounts of dissolved salts are excluded from the

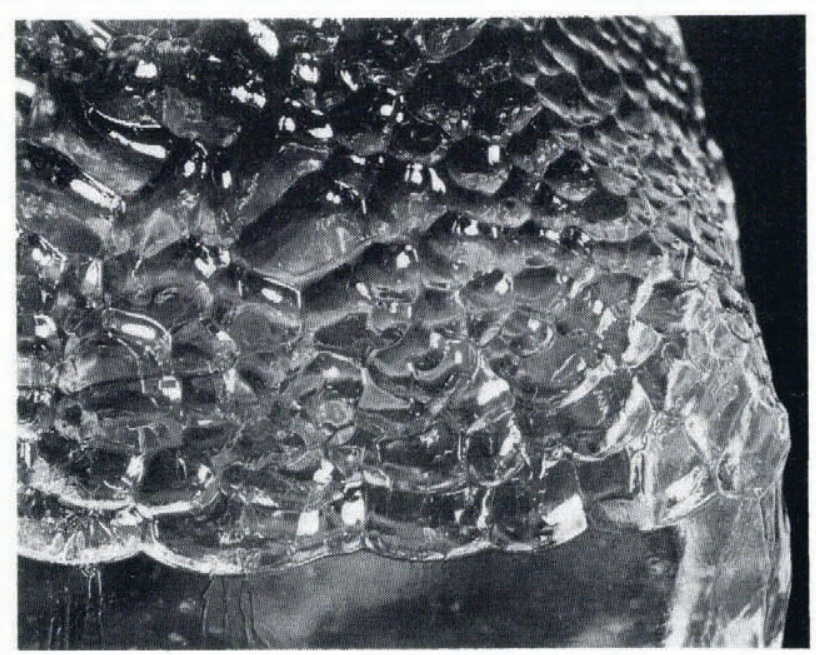

Fig. 2. 
ice-crystal structure into interstitial spaces. A similar process called brine drainage removes the salt from first-year sea ice when the ice warms in the spring.

I thank Peter Kauffman for taking these excellent photographs.

U.S. Department of the Interior, Geological Survey, Ice Dynamics Project, University of Puget Sound, Tacoma, Washington 98416, U.S.A.

4 February 1981 (revised 13 July 1981)

\section{REFERENCES}

Josberger, E. G. [ [ 1978.$]$ A laboratory and field study of iceberg deterioration. (In Husseiny, A. A., ed. Iceberg utilization. Proceedings of the first International Conference and Workshops on Iceberg Utilization for Fresh Water Production, Weather Modification, and Other Applications held at Iowa State University, Ames, Iowa, USA, October 2-6, 1977. New York, etc., Pergamon Press, p. 245-64.)

Krishnamurti, R. 1968. Finite amplitude convection with changing mean temperature. Journal of Flyid Mechanics, Vol. 33, Pt. 3, p. 445-63.

Timco, G. W., and Coveney D. B. 1980. A peculiar melt pattern in fresh-water ice. Journal of Glaciology, Vol. 25, No. 93, p. 499-501. [Letter.]

Turner, J. S. 1973. Buoyancy effects in fluids. Cambridge, Cambridge University Press. 